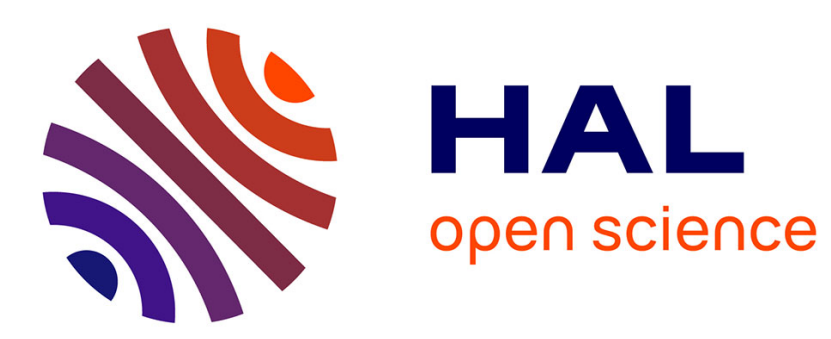

\title{
In-vivo opto-thermal measurement of epidermal thickness
}

R. Bindra, R. Imhof, G. Eccleston

\section{To cite this version:}

R. Bindra, R. Imhof, G. Eccleston. In-vivo opto-thermal measurement of epidermal thickness. Journal de Physique IV Proceedings, 1994, 04 (C7), pp.C7-445-C7-448. 10.1051/jp4:19947103 . jpa-00253155

\section{HAL Id: jpa-00253155 https://hal.science/jpa-00253155}

Submitted on 1 Jan 1994

HAL is a multi-disciplinary open access archive for the deposit and dissemination of scientific research documents, whether they are published or not. The documents may come from teaching and research institutions in France or abroad, or from public or private research centers.
L'archive ouverte pluridisciplinaire HAL, est destinée au dépôt et à la diffusion de documents scientifiques de niveau recherche, publiés ou non, émanant des établissements d'enseignement et de recherche français ou étrangers, des laboratoires publics ou privés. 


\title{
In-vivo opto-thermal measurement of epidermal thickness
}

\author{
R.M.S. Bindra, R.E. Imhof and G.M. Eccleston* \\ Department of Physics and Applied Physics, Strathclyde University, Glasgow G4 ONG, U.K. \\ * Department of Pharmacological Sciences, Strathclyde University, Glasgow G4 ONG, U.K.
}

\begin{abstract}
We report a new opto-thermal method of measuring epidermal thickness in-vivo, using thermal waves generated within the epidermis which reach the surface after transit delays that depend on depth. The method is illustrated with a thickness map of a forearm, a tape stripping sequence and subsequent wound healing.
\end{abstract}

\section{INTRODUCTION}

Epidermal thickness varies with individual and body site, generally being thinnest on the eyelids $(\approx 5 \mu \mathrm{m})$ and thickest on the soles of the feet $(\approx \mathrm{mm})$. Despite the importance of this parameter for studying transdermal diffusion and wound healing, there are no methods available for its non-destructive measurement in-vivo.

\section{MEASUREMENT PRINCIPLE}

The method reported here uses the delayed thermal wave effect first observed by Tam and Sullivan [1] in a sample consisting of a transparent polyester film on a black rubber substrate. Similar effects have been observed in human skin when a near-surface absorber, such as blood associated with bruising [2] or port wine stains [3], was visible.

The present work reports the first observation of delayed thermal waves in normal human skin. We use opto-thermal transient emission radiometry with an excitation wavelength of $532 \mathrm{~nm}$, which passes with little attenuation through the stratum corneum and epidermis, but is absorbed strongly by blood and other coloured components beneath. The thermal waves so generated are detected radiometrically as they reach the surface, after a transit delay, $\Delta t$, that depends on epidermis thickness, $\Delta z$, and thermal diffusivity, $D$. The resulting opto-thermal impulse response curves have the characteristic form illustrated as curve (1) in Figure 1. This can be

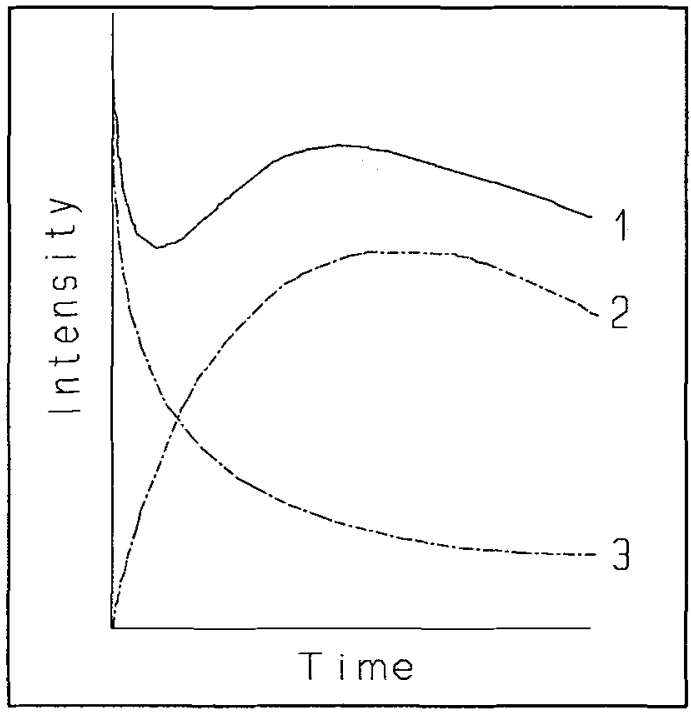

Figure 1: Observed impulse response curve (1) shown as a superposition of a rapidly decaying initial peak from the surface (3) and a broad delayed peak (2) from within the epidermis. 
interpreted as consisting of a rapidly decaying initial peak (curve 3) arising from absorption close to the surface, followed by a broad delayed peak (curve 2) originating from within the epidermis. The distortion of the delayed thermal wave by the decay of the initial peak can, in the absence of an ab initio theory, be allowed for using non-linear least squares analysis with an empirical model such as

$$
S(t)=A_{1} e^{t / \tau_{1}} \operatorname{erfc}\left(\sqrt{t / \tau_{1}}\right)+A_{2} e^{-t / \tau_{2}}+A_{3} e^{-t / \tau_{3}}
$$

where $S(t)$ is the observed signal. Quantities $A_{1}$ and $\tau_{1}$ relate to the rapidly decaying initial peak of a semiinfinite homogeneous material, while $A_{2}, A_{3}, \tau_{2}$ and $\tau_{3}$ describe the delayed thermal wave as a difference of two exponentials, whose peak delay, $\Delta t$, is given by

$$
\Delta t=\frac{\tau_{2} \tau_{3}}{\tau_{2}-\tau_{3}} \ln \left(\frac{A_{3} \tau_{2}}{A_{2} \tau_{3}}\right)
$$

The thickness $\Delta z$ can then be calculated assuming one dimensional diffusion, for which

$$
\Delta z=\sqrt{2 D \Delta t}
$$

Whilst the above analysis is unlikely to give high absolute accuracy, it nevertheless allows relative changes of epidermis thickness to be measured, while more adequate theoretical descriptions are sought.

\section{RESULTS}

The measurements were performed with a conventional OTTER apparatus (eg [4]) using a Spectron Qswitched Nd:YAG laser, producing pulses of $532 \mathrm{~nm}$ wavelength, $15 \mathrm{~ns}$ duration and $3 \mathrm{~Hz}$ repetition frequency. Thermal radiations were detected from an area of $\sim 1 \mathrm{~mm}^{2}$ with a liquid nitrogen cooled

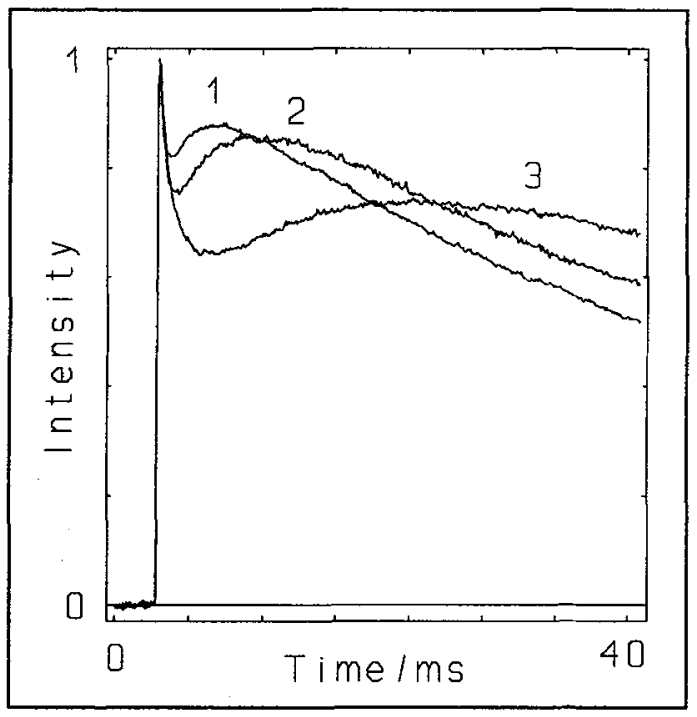

Figure 2: Delayed thermal wave signals from 1 (elbow), 2 (mid-arm), 3 (wrist).

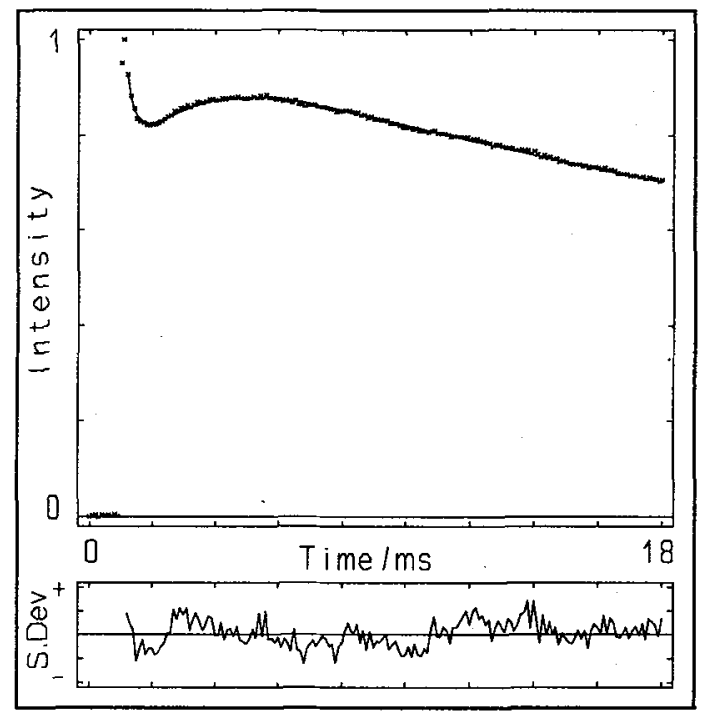

Figure 3: Least squares analysis of a delayed thermal wave signal. The data and best-fit function are shown in the top box, with residuals below to indicate deviations from the model. 
CdHgTe detector and signal averaged using a transient digitiser linked to a $\mathrm{PC}$ via a high speed parallel interface. Before each experiment, the skin was prepared by washing thoroughly with soap and allowing it to recover for half an hour, whilst remaining at rest within the laboratory. Forearms were shaved the day before, to eliminate signals from hair.

\subsection{Individual and site variations}

Experiments on fingers and forearms revealed wide variations in the form of the opto-thermal signal, depending on individual and skin site. Signals from the ventral surfaces of fingers showed little evidence of delayed thermal waves, probably because of the greater thickness of stratum corneum. Dorsal surfaces of fingers tended to give signals with poor differentiation between the delayed thermal wave and decaying components. Signals from the ventral surfaces of forearms were found to vary from individual to individual in the relative magnitudes of the initial and delayed peaks.

Figure 2 shows typical impulse response curves from three different parts of the ventral surface of the left forearm of a volunteer (RMSB), which illustrates how the signals change with thickness. Least squares analysis is illustrated in Figure 3, where the data and superimposed best-fit function calculated using Eq.(1) are shown in the upper display box. The residuals in the lower display box show deviations between data and fitted function and provide a sensitive test of the model. A thickness map of the forearm calculated using $D \approx 10^{-7} \mathrm{~m}^{2} \mathrm{~s}^{-1}$ for the thermal diffusivity of the epidermis, is shown in Figure 4 . It consists of measurements at the centres of a grid of $10 \times 3$ rectangles of $\approx 25 \times 20 \mathrm{~mm}$ each, extending from the wrist to the elbow and across the arm from the radius to the ulna. The map clearly shows how the epidermis is thinner near the elbow and radial, and thickens towards the wrist and ulna. The thickness near the wrist may well be larger than indicated in the map, because of a systematic measurement error caused by AC coupling of the detector, which increases with thickness.

\subsection{Tape stripping and wound healing}

The method was also used to measure thickness changes resulting from stripping of skin from the forearm of the above volunteer using Sellotape. The results shown in Figure 5 indicate a progressive reduction of thickness of this site with each of the first four applications of the tape, and fluctuating readings thereafter. After ten strips, the wound was cleaned and re-measured, as indicated by the square data point in Figure 5 . The measurements correlate reasonably with the residues on the tape, which were found to correspond to the removal of $1-2 \mu \mathrm{m}$ of stratum corneum in each of the first three

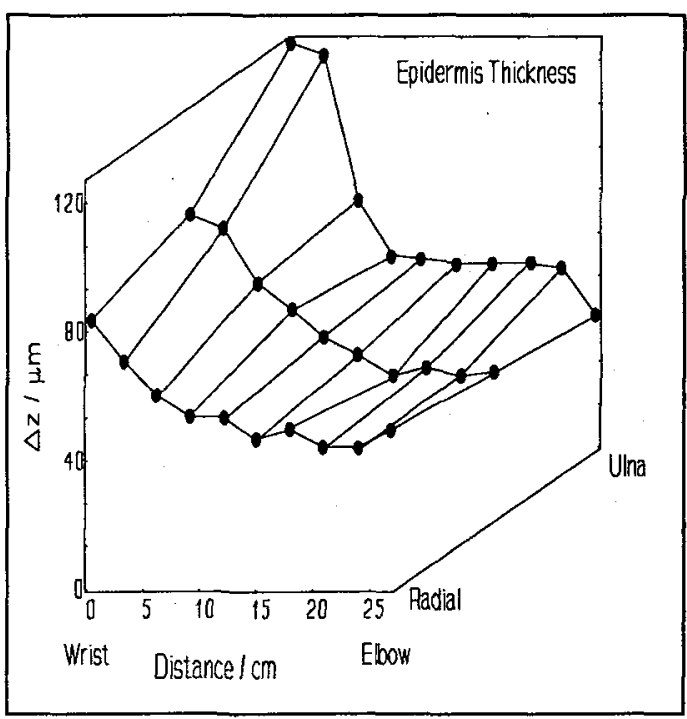

Figure 4: Epidermis thickness map of the ventral surface of the left forearm of a volunteer.

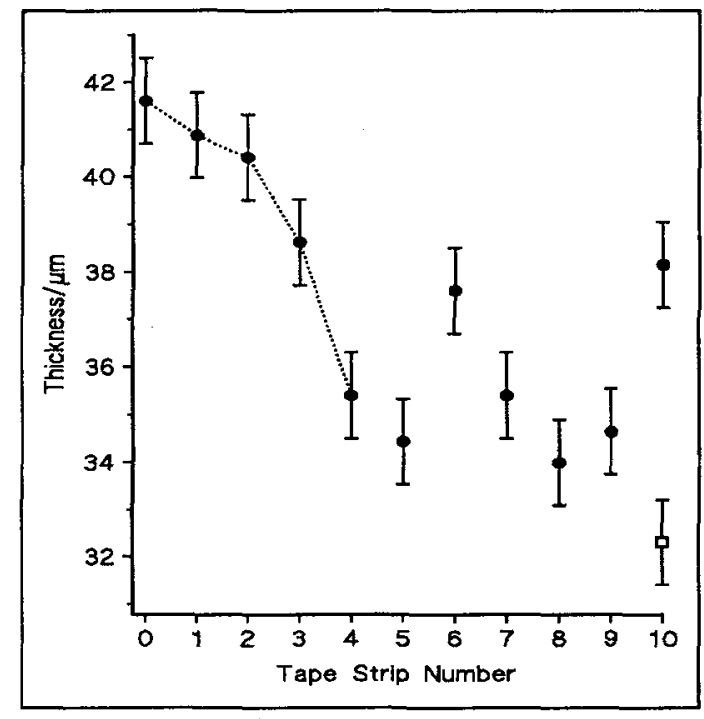

Figure 5: Epidermis thickness changes during tape stripping. The square data point was measured after washing to remove visible residues. 
applications of the tape, and $\approx 8 \mu \mathrm{m}$ in the fourth. After the fourth application, the skin looked moist and further applications removed little more. The fluctuating readings thereafter were thought to be caused by a build-up of residues on the wound. The final reading after cleaning the wound confirmed the $\approx 10 \mu \mathrm{m}$ reduction in thickness inferred from the residues on the tape.

Measurements were also made of skin thickness changes during the healing of the wound caused by tape stripping. Figure 6 shows how the thickness increased in the first few days, as a callus formed. The new stratum corneum formed beneath the callus was found to be slightly thicker than normal and did not change significantly in the ensuing several days.

\section{CONCLUSIONS}

Work is now in progress to improve quantitative understanding through an $a b$-initio theoretical model for such opto-thermal impulse response curves, and

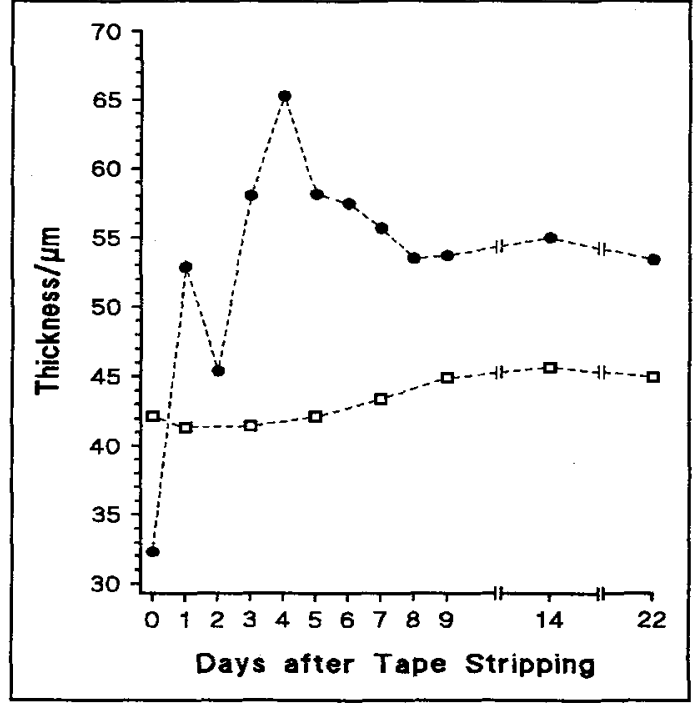

Figure 6: Epidermis thickness changes during wound healing (O) and a control site ( $\square$ ). to improve measurement accuracy through the use of DC coupling of the detector and wavelength selective detection.

\section{Acknowledgment}

We thank the SERC, Unilever and the Health \& Safety Executive for research support and John Reevie for his invaluable technical assistance.

\section{References}

[1] Tam A.C. and Sullivan B. Appl.Phys.Lett. 43(1983) 333-335.

[2] Long F.H. Anderson R.R. and Deutsch T.F. Appl.Phys.Lett. 51(1987) 2076-2078.

[3] Nelson J.S. Jacques S.L. and Wright W.J. SPIE Proc. 1643(1992) 287-298.

[4] Imhof R.E. Whitters C.J. and Birch D.J.S. Phys.Med.Biol. 35(1990) 95-102. 